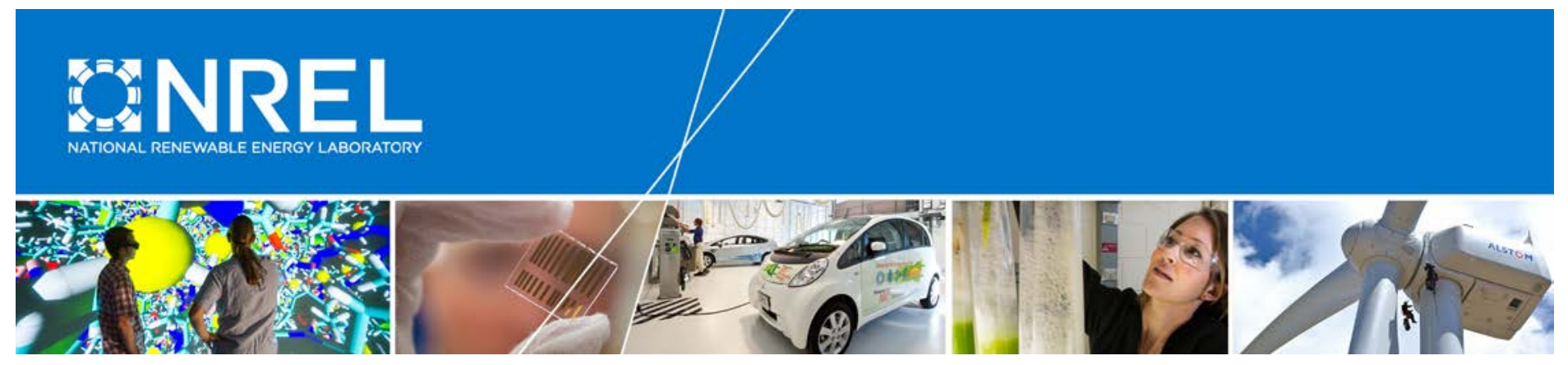

\title{
An Integrated Agent-Based and Production Cost Modeling Framework for Renewable Energy Studies
}

\section{Preprint}

Giulia Gallo

National Renewable Energy Laboratory

To be presented at the $49^{\text {th }}$ Hawaii International Conference on System Sciences (HICSS)

Kauai, Hawaii

January 5-8, 2016

NREL is a national laboratory of the U.S. Department of Energy Office of Energy Efficiency \& Renewable Energy Operated by the Alliance for Sustainable Energy, LLC

This report is available at no cost from the National Renewable Energy Laboratory (NREL) at www.nrel.gov/publications.

\section{Conference Paper}

NREL/CP-5D00-64660

October 2015 


\section{NOTICE}

The submitted manuscript has been offered by an employee of the Alliance for Sustainable Energy, LLC (Alliance), a contractor of the US Government under Contract No. DE-AC36-08GO28308. Accordingly, the US Government and Alliance retain a nonexclusive royalty-free license to publish or reproduce the published form of this contribution, or allow others to do so, for US Government purposes.

This report was prepared as an account of work sponsored by an agency of the United States government. Neither the United States government nor any agency thereof, nor any of their employees, makes any warranty, express or implied, or assumes any legal liability or responsibility for the accuracy, completeness, or usefulness of any information, apparatus, product, or process disclosed, or represents that its use would not infringe privately owned rights. Reference herein to any specific commercial product, process, or service by trade name, trademark, manufacturer, or otherwise does not necessarily constitute or imply its endorsement, recommendation, or favoring by the United States government or any agency thereof. The views and opinions of authors expressed herein do not necessarily state or reflect those of the United States government or any agency thereof.

This report is available at no cost from the National Renewable Energy Laboratory (NREL) at www.nrel.gov/publications.

Available electronically at SciTech Connect http:/www.osti.gov/scitech

Available for a processing fee to U.S. Department of Energy and its contractors, in paper, from:

U.S. Department of Energy

Office of Scientific and Technical Information

P.O. Box 62

Oak Ridge, TN 37831-0062

OSTI http://www.osti.gov

Phone: 865.576.8401

Fax: 865.576.5728

Email: reports@osti.gov

Available for sale to the public, in paper, from:

U.S. Department of Commerce

National Technical Information Service

5301 Shawnee Road

Alexandria, VA 22312

NTIS http://www.ntis.gov

Phone: 800.553 .6847 or 703.605 .6000

Fax: 703.605.6900

Email: orders@ntis.gov 


\title{
An integrated agent-based and production cost modeling framework for renewable energy studies
}

\author{
Giulia Gallo \\ National Renewable Energy Lab \\ giulia.gallo@nrel.gov
}

\begin{abstract}
The agent-based framework for renewable energy studies (ARES) is an integrated approach that adds an agent-based model of industry actors to PLEXOS and combines the strengths of the two to overcome their individual shortcomings. It can examine existing and novel wholesale electricity markets under high penetrations of renewables. ARES is demonstrated by studying how increasing levels of wind will impact the operations and the exercise of market power of generation companies that exploit an economic withholding strategy. The analysis is carried out on a test system that represents the Electric Reliability Council of Texas energy-only market in the year 2020. The results more realistically reproduce the operations of an energy market under different and increasing penetrations of wind, and ARES can be extended to address pressing issues in current and future wholesale electricity markets.
\end{abstract}

\section{Introduction}

Renewable integration studies such as $[1,2]$ have evaluated many challenges associated with deploying large amounts of variable wind and solar generation. Using production cost modeling software, these studies have evaluated the operational impacts associated with variable generation, benefits of improved wind and solar resource forecasting, and trade-offs among institutional changes. For example, the commercially available PLEXOS simulates the commitment and dispatch of the power plant fleet to meet load at least cost while maintaining system reliability. However, these types of studies have not yet considered how markets function by means of the interactions among strategic entities that compete to supply energy to the marketplace. Standard power system software tools are limited in their ability to recognize strategic behavior that might have significant impacts on market outcomes. Generation companies act strategically to maximize their own profits, subject to their real and perceived risks and technical constraints, and they are averse to the risks associated with uncertainty. The current literature on electricity markets has looked at how different market rules can affect price formation [3]-[7] and how bidding behaviors can change based on several conditions [8]-[11]. As the level of renewable energy sources on the electric grid increases, price suppressions coming from the deployment of zero-marginal-cost resources such as wind and solar may have a significant impact on the behavior of generators and decision-makers. This contributes to the discussions among power system industry actors and those who regulate it about how to design future energy markets. Another very important issue that affects energy market participants who invest in generation assets is the lack of monetary stream that can guarantee a recovery from their investments. The same issue also affects incentives to build new generation facilities if the prices do not increase because of administrative actions, such as price caps. This phenomenon is often referred to as the "missing money problem." The missing money problem is predicted by electricity market theory [12]-[14]. To address this, most North-American independent system operators (ISOs) have established longer-term markets, such as capacity markets (e.g., New York ISO, PJM, Midcontinent ISO, ISO-New England, California ISO). However, a few (e.g., Electric Reliability Council of Texas [ERCOT], the Alberta wholesale market) rely on recovering costs from energy, operating reserves, and not capacity, and they employ a price cap at the value of lost load as a correct scarcity pricing signal to incent new generation.

The main drivers for this research are (1) the need for a framework that can evaluate both operational and behavioral aspects of wholesale electricity markets and (2) to provide guidelines to assist decision makers when evaluating what-if scenarios by using an agentbased model [15]. Hence, to evaluate the impact of non-ideal actions of strategic behavior, risk aversion, and increasing levels of renewables on the electric grid, this paper presents an agent-based framework for renewable energy studies (ARES), an integrated approach that adds an agent-based model of industry 
actors to PLEXOS and combines the strengths of the two to overcome their individual shortcomings. In this paper, we use ARES to study how generation companies (Gencos) can exercise market power in an ERCOT energy-only test system that has increasing levels of wind generation.

The paper is organized as follows. Section 2 presents the ARES framework. Section 3 describes the ERCOT test system. Section 4 shows results of the tests of market power behaviors under high penetrations of wind. Section 5 validates the agentbased model. Section 6 discusses the results. Section 7 summarizes our findings.

\section{ARES}

Standard power system modeling software are useful when analyzing the existing electric grid infrastructure, but they are not flexible enough to provide what-if scenarios about how generator behaviors impact market operations. Solutions to these problems can be found by using agent-based models [14-15], which can address behavioral and technical problems and are necessary for efficient policy making related to the electricity sector. Current agent-based test beds [17]-[21] have shed light on a variety of electricity market features by using test cases and projecting the aggregated results onto existing U.S. ISOs. However, these test beds are limited in their applications by several factors, such as the availability of realistic operational models of wholesale electricity markets. ARES adds an agent-based representation of industry actors to a production cost model to study the strategic behaviors of generators under different penetrations of renewables, market designs, and simulation time horizons, as shown in Figure 1. Production cost models are formulated to minimize the total cost of generating electricity to serve energy demand in every time step by committing (determining whether a generator is on or off) and dispatching (adjusting the output of the committed generators) generators while observing constraints on operations, transmission flows, and reserves.

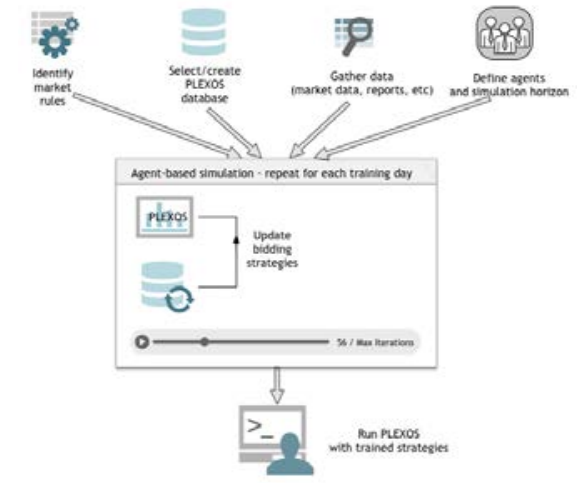

Figure 1. Flowchart of a typical ARES simulation

This computational framework can be used to represent several strategic market participants, and it is herein demonstrated on a test case as a proof of concept. Current and future work is utilizing the framework to analyze market outcomes in more complex settings and simulations. The framework can be run using high-performance computing resources, and it can simulate multiple years of operations. A typical ARES simulation is composed of three stages:

1. Calibration. During this phase, the learning algorithm is tuned after some local searching to find a set of parameters that guarantee that the agents learn the markup strategy to maximize their profits.

2. Learning. According to the learning horizon, the ARES framework simulates hourly/daily/weekly bidding strategies, and PLEXOS is called and executed a number of times as defined in the calibration phase.

3. Operation. Once the bidding behaviors have been learned, PLEXOS is executed with and without them to represent the time of operations.

\section{The ERCOT energy-only market in $\mathbf{2 0 2 0}$}

ERCOT is the nonprofit entity that operates the Texas electric grid. The ERCOT test system used in this study was derived from [23]. Below we report a summary of its major features. ERCOT has a higher capacity of natural gas generation than many other markets, but nuclear and coal generators provide more than half of the electricity generated in ERCOT. Natural-gas-fired combined-cycle plants (NGCC) comprise the majority of the installed thermal generation capacity $(41 \mathrm{GW})$. Conventional coal-fired generators, natural-gas boilers (NGB), and combustion-turbine (CT) plants make up $20 \mathrm{GW}, 12.5$ $\mathrm{GW}$, and $7.8 \mathrm{GW}$ of capacity, respectively. The system has $5.1 \mathrm{GW}$ of nuclear generation capacity, $147 \mathrm{MW}$ of biomass generation capacity, and $572 \mathrm{MW}$ of 
hydroelectric capacity. The total system capacity for the ERCOT test system is $87.7 \mathrm{GW}$, with a peak load of $77.1 \mathrm{GW}$ and a planning reserve of $13.7 \%$. The coal price for all sub-bituminous units is constant at $\$ 2.00 / \mathrm{MMBTU}$, lignite is $\$ 1.50 / \mathrm{MMBTU}$, and the natural gas $(\mathrm{NG})$ price is constant at $\$ 4 / \mathrm{MMBTU}$. This test system models two classes of operating reserves: contingency and regulating. The regulating up and regulating down requirements are set at $1 \%$ of the hourly load. The spinning reserve and non-spinning reserve requirements are set to 2,800 $\mathrm{MW}$ and 2,000 MW, respectively. The 2,800-MW spinning reserve value was set based on the largest contingency event, which is not proportional to load or to a growth in wind generation. Table 1 shows the generator parameters defined by [23] using the ERCOT LTS data [24].

\section{Table 1. ERCOT LTS input data, derived from} [22].

\begin{tabular}{|c|c|c|c|c|}
\hline Category & $\begin{array}{c}\text { Average } \\
\text { Heat } \\
\text { Rate } \\
\text { (MMBtu } \\
\text { /MWh) }\end{array}$ & $\begin{array}{c}\text { Min } \\
\text { Runtime } \\
\text { (Hours) }\end{array}$ & $\begin{array}{c}\text { VO\&M } \\
\mathbf{( \$ / M W h ) ~}\end{array}$ & $\begin{array}{c}\text { Start-Up } \\
\text { Cost } \\
\mathbf{( \$ 1 0 0 0 s )}\end{array}$ \\
\hline Nuclear & 10 & 168 & 4 & - \\
\hline Coal & 9.8 & 24 & 5 & 5 \\
\hline Biomass & 13 & 8 & 9.5 & 2.5 \\
\hline NGCC & $7.1-8.5$ & $4-6$ & $2.9-5$ & $3-15$ \\
\hline NGB & $11-17.5$ & $1-8$ & $2-8$ & 2.5 \\
\hline CT & $9.2-11.5$ & $1-2$ & $4 / 13$ & $1-10$ \\
\hline IC & 9.8 & 1 & 3 & - \\
\hline
\end{tabular}

This test system assumes an optimal, least-cost dispatch for the entire transmission system, whereas the adopted load profile is represented by the businessas-usual load profile defined in the ERCOT LTS data for the year 2020, with a minimum demand of 28.6 $\mathrm{GW}$, a peak demand of $77.1 \mathrm{GW}$, and a total electricity demand of 407 TWh. For this test case, the authors modeled five Gencos to attain some market power. Each had at least $5 \%$ of the overall capacity. The sum of the capacities from these Gencos was approximately $34 \mathrm{GW}$, which is a sizeable amount relative to the peak demand for ERCOT. All PLEXOS simulations within the ARES framework used version 6.400 R08 using the Xpress-MP 23.01.05 solver with the model performance relative gap set to $0.01 \%$ and a four-hour look-ahead period to avoid end effects.

\section{Market power issues in an agent-based model of the ERCOT system}

The literature on modeling strategic bidding in electricity markets is vast; for brevity, a brief summary is included here. The most prevalent approaches have been conducted using real bidding data by formulating several theoretical bidding mechanisms and reproducing the market outcomes that validate the theoretical and the empirical models [3], [4], [10], [25]-[30]. Computational, agent-based models that simulate the learning behaviors of market participants are loosely based on empirical facts that have been analyzed by these studies. These two modeling approaches are not in competition, but they provide different perspectives on the same matter. The latter tends to be used to model emergent behaviors in electricity markets from a computational perspective and assumes standardized yet complex behaviors that can be reproduced by simulations. The scope of our analysis is to model exercised market power by exploiting a bid-markup model that resembles economic withholding in ERCOT. The exercise of market power, either as capacity or economic withholding, is a well-known issue that can affect electricity market outcomes. Current electricity markets have implemented several methodologies to address this, such as the three pivotal supplier tests in PJM. Another example is represented by capacity markets that have been implemented in part to mitigate the capacity-withholding-based exercise of market power, as was observed during the California energy crisis.

The topic has been the subject of several research papers that looked at its modeling aspects using the agent-based paradigm. In [31] the authors analyzed market power abuse in England and Wales as part of a real regulatory inquiry that was targeting two particular generators that could potentially influence wholesale prices. The authors of [32] utilized a reinforcementlearning-based approach on a sample network as a discovery tool coupled with two well-known market power indexes, the Herfindahl-Hirschmann and the Lerner index, and two other indexes that the authors defined. However, it is well known that these two indexes are very poor indicators for electricity markets. [33] investigated market rules and market power mitigation rules using the agent-based modeling approach on a simplified representation of the PJM market. In [34], the authors modeled the EEX wholesale market with the EMCAS simulator. ERCOT itself has been subject of several studies, such as [35], in which the author studied the interaction of increasing wind, transmission constraints, production tax credits, wind and demand correlation, and electricity market prices. To our knowledge, this study is the first that specifically targets the issue of market power in an agent-based model of the ERCOT system.

ERCOT attempts to mitigate market power with an ex-ante mitigation rule, also called the "small fish rule" [36]. The Public Utility Commission of Texas's 
(PUCT's) Substantive Rule No. 25.504(c) states, “A single generation entity that controls less than $5 \%$ of the installed generation capacity in ERCOT; excluding uncontrollable renewable resources, is deemed not to have ERCOT-wide market power." PUCT Rule No. 25.5(60) defines "installed generation capacity" as including mothballed generation. As such, the most recent listing totals $81,597 \mathrm{MW}$ of capacity, and $5 \%$ of that is $4,080 \mathrm{MW}$. The rule covers only the exercise of system-wide market power, and it does not shield generators from measures designed to mitigate local market power. One of the most interesting features of agent-based frameworks is the possibility of modeling strategic behaviors to generate what-if scenarios of existing power systems. In this respect, we used the ARES framework to model Gencos that exercise market power using an economic-withholding bidding strategy. The rationale behind the economic withholding strategy is to increase the level of prices by adding a markup to the true production costs of the generators and therefore to earn more money by supplying energy. The risk of adding a markup is that only the marginal generator sets the price, and offering too high could cause the market operator to select an alternative generator with a lower offer. Therefore, the economic withholding strategy can lead to different outcomes according to the location of the generation company on the supply curve. If a generating entity operates a set of power plants that can be marginal and are positioned close to the marginal price for many time periods, it can drive up the prices and therefore earn higher profits. A generating entity that is unlikely to be marginal will not have an incentive to have a markup strategy that can place itself out of the supply curve. A generating entity that owns baseload plants will most likely bid their true production costs (assuming the entity controls less than $5 \%$ of the installed capacity). Based on the above hypotheses and assumptions, we defined generation companies (Gencos) that participate in the ERCOT energy market to implicitly have market power and to re-create an oligopoly structure.

In our ERCOT agent-based model, we chose five representative Gencos, each with an approximately equal amount of NGCC capacity (see Table 2). They own more than $5 \%$ of the model's maximum capacity (see Table 1), and this provides them with the ability to exercise market power based on the ERCOT PUCT rule [36]. The Gencos select a markup for their entire fleet of NGCCs for the daily energy market auction using a reinforcement-learning algorithm, described in Section 4.2. All of the non-NGCC generators in ERCOT are assumed to offer at their marginal cost.
Table 2. Total Capacity of the Modeled Gencos

\begin{tabular}{|c|c|c|}
\hline Genco & MW & \# of power plants owned \\
\hline G1 & $7,016 \mathrm{MW}$ & 7 \\
\hline G2 & $6,945 \mathrm{MW}$ & 11 \\
\hline G3 & $7,017 \mathrm{MW}$ & 13 \\
\hline G4 & $6,014 \mathrm{MW}$ & 14 \\
\hline G5 & $7,092 \mathrm{MW}$ & 26 \\
\hline
\end{tabular}

Electricity markets are characterized by inherent complexity and repeated games that require modeling the strategic behaviors of market participants. This task is usually achieved by endowing the market actors with learning capabilities. Computational learning is increasingly finding application as the most effective methodology to develop insights into price formation in complex markets in which there may be imperfect competition and when analytical results are elusive in all but the oversimplified stylizations. As such, electricity markets have been quite extensively analyzed in this way using a variety of learning algorithms (see [37] for a review). The literature on agent-based electricity market models points out three major types of learning algorithms: zero-intelligence algorithms [38], reinforcement and belief-based models [39], and an evolutionary approach [39]. In this paper, we modeled the strategic behaviors that the Gencos exhibited using a reinforcement-learning algorithm, the Variant Roth-Erev algorithm developed by [40]. The original Roth and Erev learning model considers three psychological aspects of human learning:

1. The power law of practice, i.e., learning curves are initially steep and tend to progressively flatten out;

2. The recency (or forgetting) effect, i.e., agents' recent experience plays a larger role than past experience in determining their behavior;

3. The experimentation effect, i.e., not only the experimented strategy but also similar strategies are reinforced.

In this model, the markup bid by the Genco on the ERCOT market represents the action that is learned using the VRE algorithm [40].

\section{Validation of the agent-based model}

The PLEXOS energy market model was tested against real historical prices in [23]. Because the simulations provide a what-if analysis for the year 2020, it is not possible to compare the simulated prices to the historical prices. In this section, the agent-based model is validated. Electricity markets around the world are characterized by distinctive phenomena: these features are typically called stylized facts [41], [42]. Examples 
of these features are price jumps or spikes, extreme volatility, seasonality, mean reversion, and an underlying probability distribution that follows power law or is hyperbolic and exhibits heavy tails. Any agent-based model that represents an electricity market should try to mimic these features to reliably and accurately depict reality, and to be eventually used to forecast electricity market prices [43]. Because there is not a standard validation process to follow when validating an agent-based model, in this paper we analyzed a sample of the monthly market prices realized with the agent-based model and studied their statistical properties. The first phenomenon that we analyzed was the non-stationarity of the price time series; when its statistical properties such as mean, variance, and autocorrelation are all constant over time, a time series is stationary. Electricity market prices are not stationary because of the intrinsic nature of the commodity being traded. This feature is usually determined by using a hypothesis test, such as the Augmented Dickey-Fuller test, whose null hypothesis is that the time series is non-stationary. Accordingly, we applied the Augmented Dickey-Fuller test to the monthly electricity market prices generated with the ARES framework. The statistic for the null hypothesis is -1.176 , and its corresponding critical values at levels $1 \%, 5 \%$, and $10 \%$ with 694 observations are -2.58 , 1.95 , and -1.62 respectively. Hence, we could not reject the null hypothesis that the time series is nonstationary at these confidence levels. Another stylized fact typical of electricity market prices is the fat-tail phenomenon: the distribution of returns displays heavy tails with positive excess kurtosis. This phenomenon is noticeable after filtering the data to remove the underlying seasonality and trend. In general, returns of market prices are more meaningful for modeling and finding heavy-tailed distributions. These are typical of power-law distributions (e.g., Pareto) and can be inspected in a log-log graph of the complementary cumulative distribution of the returns. Figure 2 shows two simulated models of returns distributions (a Power-law distribution and a log-normal distribution), and we compared them to the actual time series simulated with the behavioral framework. The market returns showed a fat-tail phenomenon, matching the simulated power-law distribution.

\section{Results and discussion}

The computational framework allows us to model how market participants interact within the ERCOT system: the outcomes from an agent-based simulation are different from the ones that are defined by a leastcost optimal dispatch that does not take strategic behavior into account.

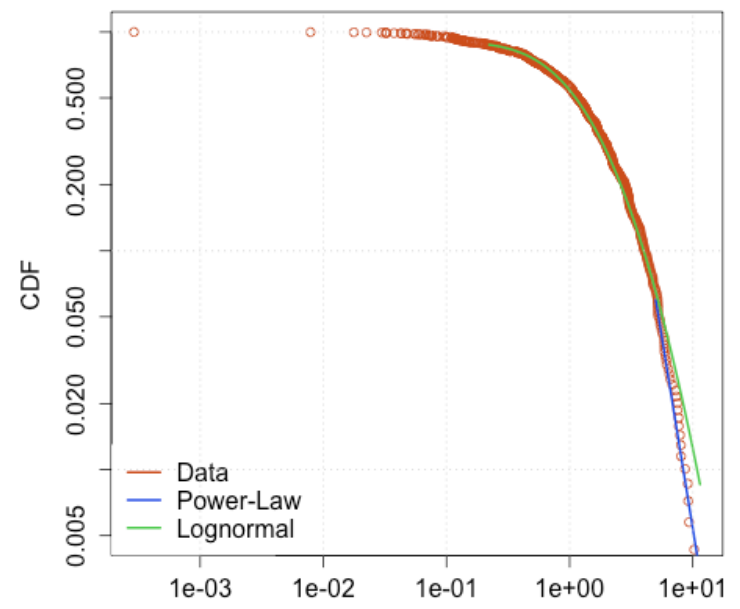

Figure 2. Fat-tail phenomenon observed in one sample of market prices obtained with the agent-based model.

This model studies how behaviors change according to a different demand profile under increasing penetration levels of wind: the simulations are carried out in a low demand and a high demand scenario, and they depict a monthly market operation. To this aim, in Section 6.1 we discuss some of the differences between the baseline scenario (referred to in the pictures as "B") and the agent-based scenario (referred to in the pictures as "A") to address the changes in the market operations as well as in the way the Gencos are exercising their market power. In Section 6.2 we discuss the effect of theoretical high penetration levels of wind in the ERCOT system in 2020 .

\subsection{Least-cost optimization vs. agent-based modeling}

The first difference between the behavioral approach and the least-cost dispatch is the level of prices: when generating entities try to increase the level of prices to increase their profits accordingly, if they are successfully in doing so, the general level of prices will be higher. This difference is shown in Figure 3: the top graph shows a sample of the different wind penetration scenarios during the high demand scenario, and the bottom graph shows the same sample of scenarios during the low demand scenario. However, a higher price is not a straightforward consequence of adding a behavioral layer on top of a production-cost software. Indeed, PLEXOS could still determine that the generators that are being strategically offered by the Gencos, are less economical, and as such, are not scheduled to be dispatched and decrease how the Gencos' market 
power is exercised, and therefore decrease the generation supplied by the Gencos. We can see these effects in Figure 4, where we compare three Gencos' energy dispatch in all scenarios and under different wind penetration levels.
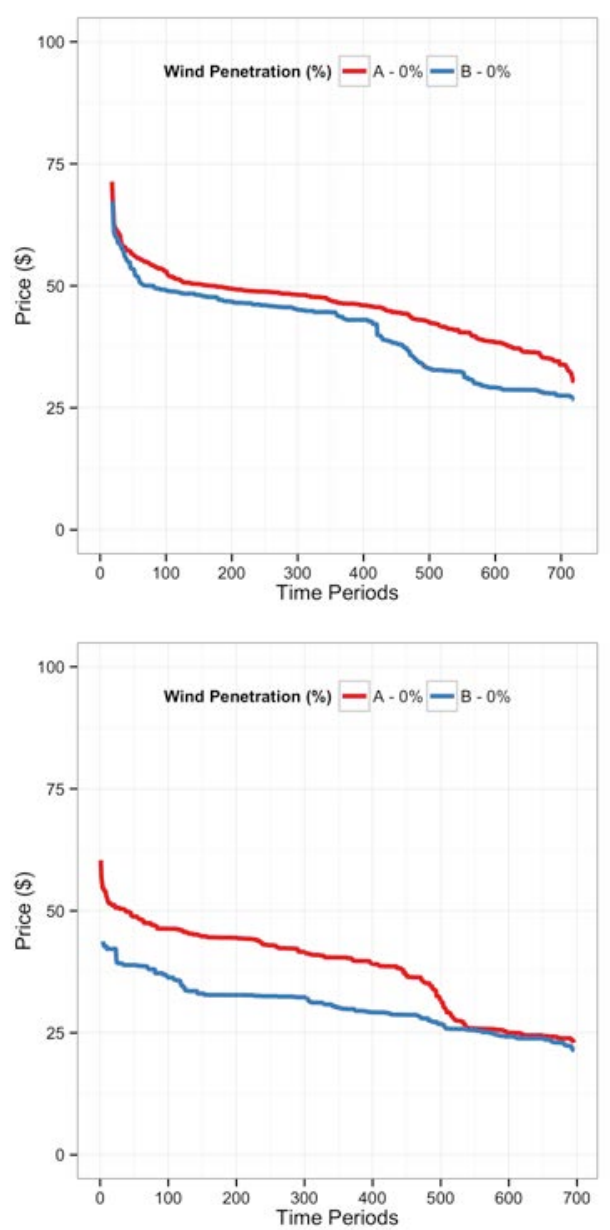

Figure 3. Price duration curve comparison between the high demand scenario (top graph) and the low demand scenario (bottom graph).

Baseline scenario $=B$, agent-based scenario $=\mathrm{A}$

It is clear from the two graphs that the Gencos were able to strategically supply more energy on the market in the low demand scenario, but they did not in the high demand scenario. This might be considered one of the limitations of the currently implemented bidding strategy that does not assume temporal variations, i.e., the markups do not change within the two demand scenarios However, if the Gencos are generating less supply when they are strategic, how does this outcome affect their exercise of market power and their profits? Figure 5 represents the number of hours during which each of the Gencos had a unit that was marginal throughout the simulation. This result depicts how the Gencos were able to strategically raise the levels of prices using the economic withholding strategy and also set the market prices.

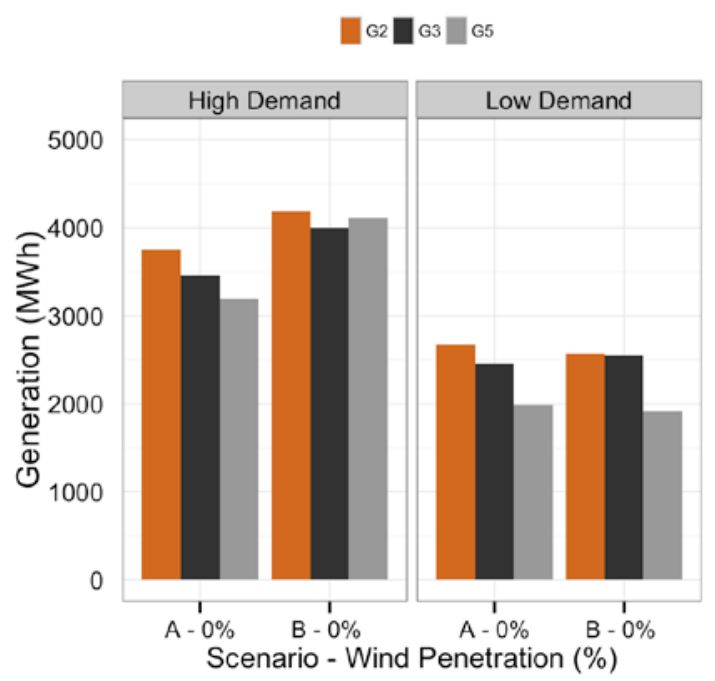

Figure 4. Dispatched energy comparison between the high demand and low demand scenarios for three representative Gencos.

Baseline scenario $=B$, agent-based scenario $=\mathrm{A}$

In general, almost all Gencos were able to set the price when they were strategic in both demand scenarios. In particular, Genco 5 benefited the most from the training session, because it could double the hours (total) during which it was marginal with its owned generators (therefore setting the price in the ERCOT region). The effect of wind on the Gencos' ability to set the market price of course increased as wind increased in the system. In this respect, all Gencos could not set the price as much as they did in the no wind scenario or the low wind scenario $(8 \%)$. Genco 5 appeared to be setting the price most in the high demand scenario, with $18 \%$ wind penetration. The behavioral model was also able to show what the overall Gencos profits would look like in a market environment. From the above discussion, we have shown that the Gencos supplied less energy to the market when they bid, they increased their ability to set the market price, and they accordingly increased the general level of prices. Figure 6 reports the distribution of the profits made by the Genco agents in the two demand scenarios and under different wind penetrations. 

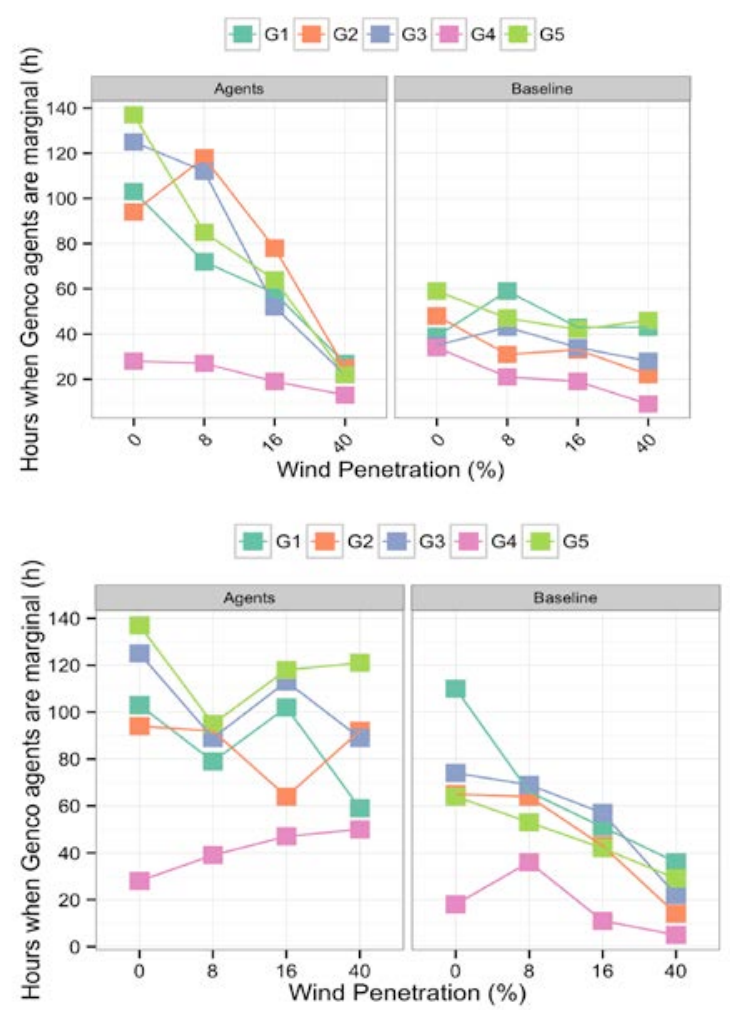

Figure 5. Difference in setting the marginal price between the Gencos in the high demand scenario (top graph) and low demand scenario (bottom graph)

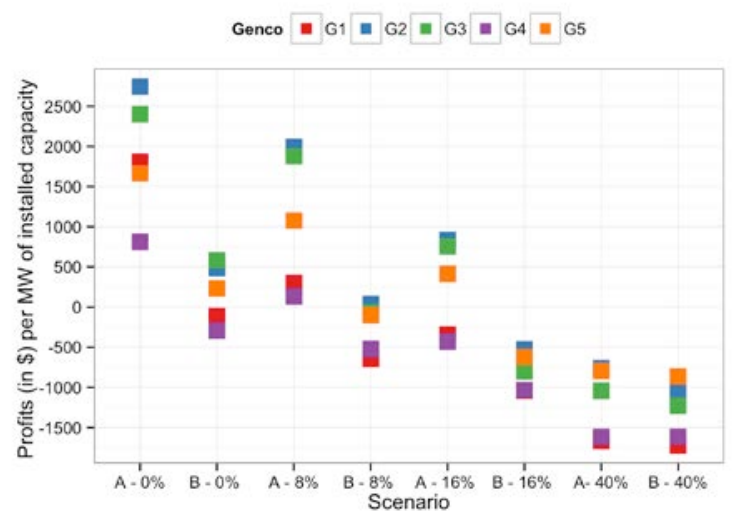

Figure 6. Distribution of each Gencos profits within the simulation. Profits have been normalized by each Gencos total capacity. Baseline scenario $=\mathrm{B}$, Agent-based scenario $=\mathrm{A}$

The bidding strategy allowed the Gencos to maximize their profits and to produce less energy than they did under a least-cost dispatch model. This result is not in contradiction with what we have shown above. Finally, Table 3 reports the change in the ability

of exercising market power by all Gencos throughout the simulations. The behavioral simulation, even without a high level of sophistication, allowed for a better representation of how generating entities can have an impact on the operation of an energy market under increasing wind penetrations. Profits in the low demand scenario consistently decreased and assumed negative values for all Gencos. It is worth mentioning that the model currently does not take into account the possibility of receiving make-whole payments when profits are negative. This is an offline feature that will be added in the next release of the ARES framework. By adding this feature, the profits would have a minimum value of zero.

Table 3. Percentage of hours with respect to the two months of simulation during which the Gencos were marginal. Baseline scenario $=B$, Agent-based scenario $=\mathrm{A}$

\begin{tabular}{|c|c|c|c|c|c|c|c|c|}
\hline $\begin{array}{c}\text { Wind } \\
\text { penetrati } \\
\text { on }\end{array}$ & \multicolumn{2}{|c|}{$0 \%$} & \multicolumn{2}{|c|}{$8 \%$} & \multicolumn{2}{|c|}{$16 \%$} & \multicolumn{2}{c|}{$40 \%$} \\
\hline $\begin{array}{c}\text { Genco/Sc } \\
\text { enario }\end{array}$ & $\mathrm{A}$ & $\mathrm{B}$ & $\mathrm{A}$ & $\mathrm{B}$ & $\mathrm{A}$ & $\mathrm{B}$ & $\mathrm{A}$ & $\mathrm{B}$ \\
\hline $\mathrm{G} 1$ & $\begin{array}{c}14 \\
\%\end{array}$ & $\begin{array}{c}15 \\
\%\end{array}$ & $\begin{array}{c}12 \\
\%\end{array}$ & $9 \%$ & $8 \%$ & $6 \%$ & $6 \%$ & $5 \%$ \\
\hline $\mathrm{G} 2$ & $\begin{array}{c}13 \\
\%\end{array}$ & $9 \%$ & $\begin{array}{c}12 \\
\%\end{array}$ & $6 \%$ & $\begin{array}{c}12 \\
\%\end{array}$ & $5 \%$ & $6 \%$ & $2 \%$ \\
\hline $\mathrm{G} 3$ & 17 & 10 & $\begin{array}{c}15 \\
\%\end{array}$ & $8 \%$ & $\begin{array}{c}10 \\
\%\end{array}$ & $6 \%$ & $7 \%$ & $3 \%$ \\
\hline $\mathrm{G} 4$ & $4 \%$ & $2 \%$ & $5 \%$ & $4 \%$ & $5 \%$ & $2 \%$ & $3 \%$ & $1 \%$ \\
\hline $\mathrm{G} 5$ & 19 & $9 \%$ & $\begin{array}{c}14 \\
\%\end{array}$ & $7 \%$ & $\begin{array}{c}13 \\
\%\end{array}$ & $6 \%$ & $8 \%$ & $5 \%$ \\
\hline TOT & $\begin{array}{c}\mathbf{6 7} \\
\%\end{array}$ & $\begin{array}{c}\mathbf{4 5} \\
\%\end{array}$ & $\begin{array}{c}\mathbf{5 8} \\
\%\end{array}$ & $\begin{array}{c}\mathbf{3 4} \\
\%\end{array}$ & $\begin{array}{c}\mathbf{4 8} \\
\%\end{array}$ & $\begin{array}{c}\mathbf{2 5} \\
\%\end{array}$ & $\begin{array}{c}\mathbf{3 0} \\
\%\end{array}$ & $\begin{array}{c}\mathbf{1 6} \\
\%\end{array}$ \\
\hline
\end{tabular}

\subsection{The effect of high penetration levels of wind on the ERCOT test system}

We begin with an examination of the operation of the ERCOT test system in all renewable scenarios performed using the behavioral model. Figure 7 shows the two monthly generation mixes of the wind scenario. At low penetrations, wind tended to displace natural gas generators. As wind penetration increased, coal began to be displaced, particularly when demand is low (top panel). Overall, the introduction of zeromarginal-cost renewables displaced fossil-fueled generation, reducing their capacity factors and revenues. There was also a strong interaction among wind level and prices, which can be influenced by generator strategic behavior.

Figure 8 shows the price duration curves for the two monthly simulations under increasing penetrations of wind. As shown, prices were determined by the marginal generators on the system at a given time 
interval. As wind penetration increased and gas was displaced, the number of hours with coal (the less expensive fuel) on the margin increased. However, there were also an increased numbers of hours when the high amount of wind (especially in the low demand scenario; bottom panel of Figure 8) was the marginal unit in the system. It is worth noting that we did not explicitly consider any bidding strategy that a wind generator can have in the energy market (e.g., bidding their production tax credit); including this feature would suppress more the prices to negative values because wind generators bid negative costs.
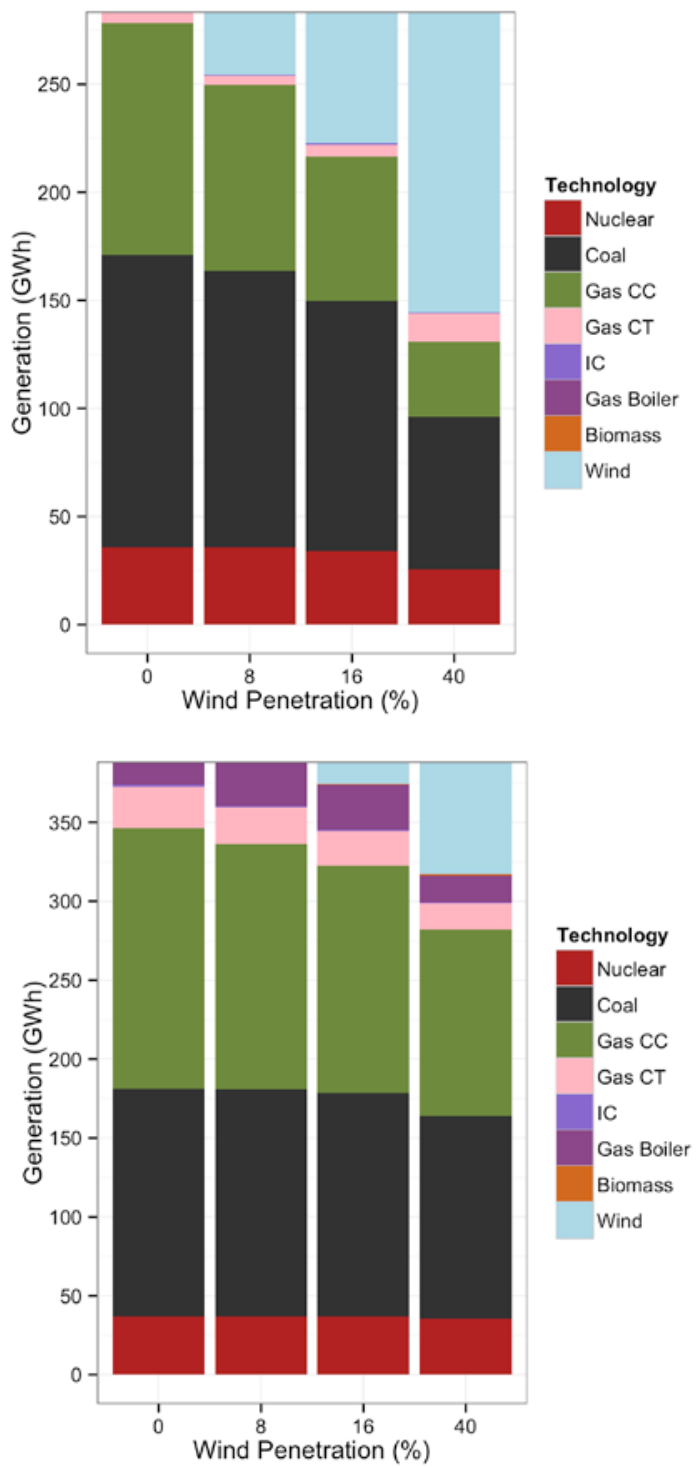

Figure 7. Breakdown of high demand (top panel) and low demand (bottom panel) generation by type.
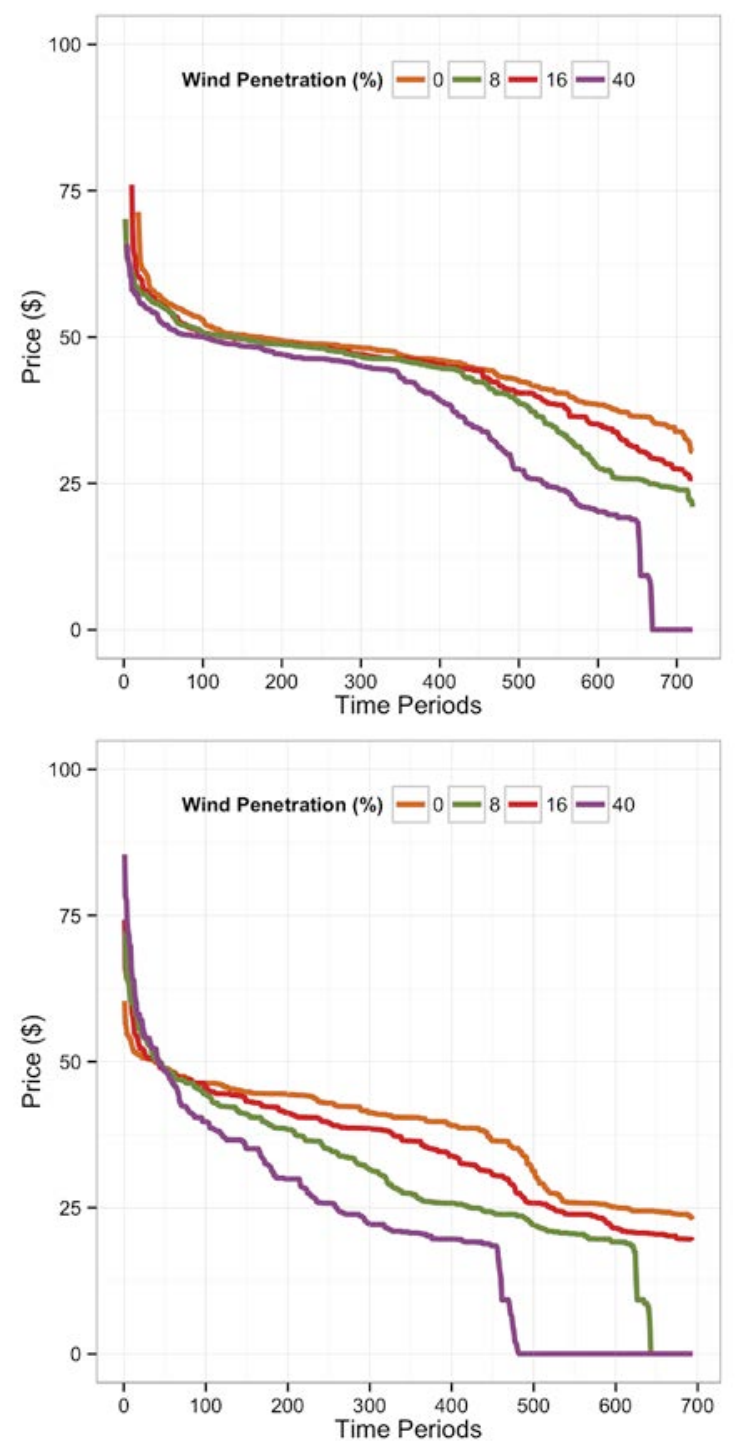

Figure 8. Price duration curves for the low demand scenario (bottom panel) and the high demand scenario (top panel).

In a high demand scenario, and with the ability of being marginal by actually bidding higher than their marginal costs, Gencos can gain high profits. This is reported in Table 4, which presents the Gencos average markups in the high demand scenario. However, to keep earning money once wind in the system increases, Gencos have to increase their markup levels, both in the low demand and the high demand scenarios. In doing so, the agents are profiting less with high wind penetrations. 
Table 4. Average markup levels in the two demand scenarios.

\begin{tabular}{|c|c|c|c|c|c|}
\hline Scenario & $\begin{array}{c}\text { Genco/Wind } \\
\text { Penetration }\end{array}$ & $\mathbf{0 \%}$ & $\mathbf{8 \%}$ & $\mathbf{1 6 \%}$ & $\mathbf{4 0 \%}$ \\
\hline \multirow{3}{*}{$\begin{array}{c}\text { High } \\
\text { Demand }\end{array}$} & G1 & 12.0 & 20.0 & 20.1 & 17.1 \\
\cline { 2 - 6 } & G2 & 9.4 & 9.0 & 16.4 & 21.6 \\
\cline { 2 - 6 } & G3 & 11.6 & 12.1 & 14.0 & 17.5 \\
\cline { 2 - 6 } & G4 & 13.5 & 18.0 & 18.0 & 23.0 \\
\cline { 2 - 6 } & G5 & 12.0 & 13.0 & 15.7 & 19.2 \\
\hline
\end{tabular}

\begin{tabular}{|c|c|c|c|c|c|}
\hline \multirow{3}{*}{ Low } & G1 & 8.6 & 9.3 & 8.6 & 10.1 \\
\cline { 2 - 6 } & G2 & 11.7 & 9.6 & 11.2 & 9.6 \\
\cline { 2 - 6 } & G3 & 11.5 & 11.7 & 13.0 & 12.7 \\
\cline { 2 - 6 } & G4 & 10.5 & 10.2 & 10.2 & 10.0 \\
\cline { 2 - 6 } & G5 & 12.6 & 13.0 & 14.0 & 13.2 \\
\hline
\end{tabular}

\section{Conclusions}

With an increase in the level of renewable energy sources deployed in the power system at zero cost, price suppression may have a significant impact on the behavior of generators, the power system industry, and those who regulate it. To evaluate the impact of nonideal actions of strategic agents this paper has presented ARES, an integrated research framework that adds an agent-based model of industry actors to PLEXOS. The framework has been demonstrated by depicting how a test system that represents the ERCOT energy-only market might operate in 2020 under high penetration levels of wind. We studied how generation companies that are deemed to have and exercise market power do so in a test system that represents the ERCOT market by reproducing their decision-making processes in an agent-based model. Given the novelty of this modeling approach, we presented some differences between a standard, least-cost, production modeling simulation and a behavioral one. The agent framework improved the realism of the model as follows: It increased generator profits compared to simple marginal-cost bidding; the level of the market prices was higher when strategic resources tried to increase their profits, bidding their true production costs and a markup. The bidding strategy helped the Gencos to supply less energy but at a higher economic reward. However, the impact of high penetrations of wind reduced the Gencos ability to manipulate the prices. The results obtained with the agent framework reproduce with more realism the operations of an energy market under different and increasing wind penetrations. There are many open questions that the framework can address, and further analyses will investigate more sophisticated bidding behaviors and how generating entities can recover from their capital costs under current or future electricity markets.

\section{Acknowledgments}

The author gratefully acknowledges the support and feedback from the following individuals from the National Renewable Energy Laboratory (NREL): Michael Milligan for helpful discussions on electricity market design; Aaron Townsend for helpful discussions, guidance, and the ERCOT PLEXOS model; Clayton Barrows, Jennie Jorgenson, Greg Brinkman, Aaron Bloom, and Paul Denholm in the Strategic Energy Analysis Center; and Anthony Florita and Hongyu $\mathrm{Wu}$ in the Transmission Grid and Integration Group. This work was supported by the U.S. Department of Energy under Contract No. DEAC36-08GO28308 with NREL. Funding was provided by the NREL Laboratory Directed Research and Development Director's Fellowship Program.

\section{References}

[1] D. Lew, G. Brinkman, E. Ibanez, B.-M. Hodge, M. Hummon, A. Florita, and M. Heaney, "Western Wind and Solar Integration Study Phase 2," NREL, Golden, CO, TP5500-55588, 2013.

[2] A. Bloom, A. Townsend, D. Palchak, King J, E. Ibanez, Barrows C, M. Hummon, and Draxl C, "Eastern Renewable Generation Integration Study," NREL, Golden, CO, TP-6A20-64472, 2015.

[3] F. A. Wolak, Market design and price behavior in restructured electricity markets: an international comparison. Springer, 2000.

[4] F. A. Wolak and R. H. Patrick, "The impact of market rules and market structure on the price determination process in the England and Wales electricity market," National Bureau of Economic Research, 2001.

[5] D. Hurlbut, K. Rogas, and S. Oren, "Protecting the market from 'hockey stick' pricing: how the Public Utility Commission of Texas is dealing with potential price gouging," Electr. J., vol. 17, pp. 26-33, 2004.

[6] S. Oren, "When is a pay-as bid preferable to uniform price in electricity markets," presented at the Power Systems Conference and Exposition, 2004, vol. 3, pp. 16181620.

[7] R. Sioshansi, S. Oren, and R. O'Neill, “Three-part auctions versus self-commitment in day-ahead electricity markets," Util. Policy, vol. 18, pp. 165-173, 2010.

[8] A. Hortacsu and S. L. Puller, "Understanding strategic bidding in multi-unit auctions: a case study of the Texas electricity spot market," RAND J. Econ., vol. 39, pp. 86-114, 2008.

[9] S. S. Oren, "Market structure, market rules and market behavior in a competitive electricity industry," presented at the Power Engineering Society Winter Meeting, 2001. IEEE, 2001, vol. 1, pp. 45-49.

[10] R. Sioshansi and S. Oren, "How good are supply function equilibrium models: an empirical analysis of the ERCOT balancing market," J. Regul. Econ., vol. 31, pp. 1$35,2007$. 
[11] G. Gallo, L. Ponta, and S. Cincotti, "Profit-based O \&M strategies for wind power plants," in European Energy Market (EEM), 2012 9th International Conference on the, 2012, pp. 1-7.

[12] P. Joskow and J. Tirole, "Reliability and competitive electricity markets," RAND J. Econ., vol. 38, pp. 60-84, 2007.

[13] W. Hogan, “On an 'Energy only' electricity market design for resource adequacy," 2005.

[14] P. Cramton and S. Stoft, "The convergence of Market Designs and Adequate Generating Capacity," 2006.

[15] J. D. Farmer and D. Foley, "The economy needs agent-based modelling," Nature, vol. 460, pp. 685-686, 06/print 2009.

[16] R. Axelrod, "Advancing the Art of Simulation in the Social Sciences," in Simulating Social Phenomena, vol. 456, R. Conte, R. Hegselmann, and P. Terna, Eds. Springer Berlin Heidelberg, 1997, pp. 21-40.

[17] R. Axtell, "Why agents?: on the varied motivations for agent computing in the social sciences.," 2000.

[18] G. Conzelmann, G. Boyd, V. Koritarov, and T. Veselka, "Multi-agent power market simulation using EMCAS," presented at the Power Engineering Society General Meeting, 2005. IEEE, 2005, pp. 2829-2834 Vol. 3. [19] I. Praca, C. Ramos, Z. Vale, and M. Cordeiro, "MASCEM: a multiagent system that simulates competitive electricity markets," Intell. Syst. IEEE, vol. 18, pp. 54-60, 2003.

[20] A. Weidlich and D. Veit, "Analyzing interrelated markets in the electricity sector \&\#x2014; The case of wholesale power trading in Germany," presented at the Power and Energy Society General Meeting - Conversion and Delivery of Electrical Energy in the 21st Century, 2008 IEEE, 2008, pp. 1-8.

[21] J. Sun and L. Tesfatsion, "Dynamic Testing of Wholesale Power Market Designs: An Open-Source AgentBased Framework," Comput. Econ., vol. 30, pp. 291-327, Oct. 2007.

[22] S. Cincotti and G. Gallo, "The Genoa Artificial Power-Exchange," in Agents and Artificial Intelligence, vol 358, J. Filipe and A. Fred, Eds. Springer Berlin Heidelberg, 2013, pp. 348-363.

[23] A. Townsend, "A grid-level assessment of compressed air energy storage in ERCOT," The University of Texas at Austin, Austin, Texas, USA, 2013.

[24] ERCOT, "ERCOT Long-Term Study Task Force Meeting." 2011.

[25] S. Borenstein, J. Bushnell, and F. Wolak, "Diagnosing market power in California's restructured wholesale electricity market," National Bureau of Economic Research, 2000.

[26] J. Bushnell and F. Wolak, "Regulation and the leverage of local market power in the California electricity market," UC Berkeley Compet. Policy Cent. No CPC00-13, 2000.

[27] A. Jha and F. A. Wolak, "Testing for market efficiency with transactions costs: An application to convergence bidding in wholesale electricity markets," Technical report, Stanford University, 2013.
[28] S. D. McRae and F. A. Wolak, "How do firms exercise unilateral market power? Evidence from a bid-based wholesale electricity market," 2009.

[29] F. Wolak, "Managing unilateral market power in electricity," World Bank Policy Res. Work. Pap., 2005.

[30] F. A. Wolak, "Measuring unilateral market power in wholesale electricity markets: the California market, 19982000," Am. Econ. Rev., pp. 425-430, 2003.

[31] D. Bunn and F. Oliveira, "Evaluating Individual Market Power in Electricity Markets via Agent-Based Simulation," Ann. Oper. Res., vol. 121, pp. 57-77, Jul. 2003. [32] V. Nanduri and T. K. Das, "A Reinforcement Learning Model to Assess Market Power Under AuctionBased Energy Pricing," Power Syst. IEEE Trans. On, vol. 22, pp. 85-95, 2007.

[33] Y. Nan-Peng, L. Chen-Ching, and J. Price, "Evaluation of Market Rules Using a Multi-Agent System Method," Power Syst. IEEE Trans. On, vol. 25, pp. 470-479, 2010 .

[34] J. Wang, A. Botterud, G. Conzelmann, and V. S. Koritarov, "Market power analysis in the EEX electricity market: An agent-based simulation approach," presented at the Power and Energy Society General Meeting - Conversion and Delivery of Electrical Energy in the 21st Century, 2008 IEEE, 2008, pp. 1-8.

[35] R. Baldick, "Wind and Energy Markets: A Case Study of Texas," Syst. J. IEEE, vol. 6, pp. 27-34, 2012.

[36] PUCT, "PUCT's Substantive Rule No. 25.504(c),."

[37] A. Weidlich and D. Veit, "A critical survey of agent-based wholesale electricity market models," Energy Econ., vol. 30, pp. 1728-1759, 2008.

[38] D. D. K. Gode and S. Sunder, "Double auction dynamics: structural effects of non-binding price controls," $J$. Econ. Dyn. Control, vol. 28, pp. 1707-1731, 2004.

[39] C. Camerer and T. Hua Ho, "Experience-weighted Attraction Learning in Normal Form Games," Econometrica, vol. 67, pp. 827-874, 1999.

[40] M. Pentapalli, "A comparative study of Roth-Erev and modified Roth-Erev reinforcement learning algorithms for uniform-price double auctions," Iowa State University, Computer Science Department, 2008.

[41] B. LeBaron and P. Winker, "Introduction to the Special Issue on Agent-Based Models for Economic Policy Advice," Jahrb. Für Natl. Stat. J. Econ. Stat., vol. 228, pp. 141-148, 2008.

[42] R. Weron, M. Bierbrauer, and S. Trück, "Modeling electricity prices: jump diffusion and regime switching,"

Hugo Steinhaus Center, Wroclaw University of Technology, HSC Research Reports HSC/03/01, 2003.

[43] S. Cincotti, G. Gallo, L. Ponta, and M. Raberto, "Modeling and forecasting of electricity spot-prices: Computational intelligence vs classical econometrics," AI Commun., vol. 27, no. 3, pp. 301-314, 2014. 